\title{
Foreword
}

\section{Mercury Electrodes are Indispensable Tools for Membrane Research}

\section{Fritz Scholz}

Without the outstanding properties of mercury, electroanalytical chemistry, especially voltammetric analysis, would not have developed as it did. Jaroslav Heyrovský and his famous Czech school established both the theoretical and experimental basis of polarography, and obtained a wealth of data that would have been unattainable on solid electrodes. Although everyone today understands the toxic effects of mercury in the environment, it is very strange that the use of this metal remains tightly restricted in many research laboratories, and has even been banned in some countries. Chemists are used to handling much more dangerous substances, and modern mercury electrodes possess a very high degree of safety. Anyone who has compared the performance of mercury electrodes with solid electrodes knows that the voltammetric response is incomparably better on mercury electrodes.
Actually, the use of mercury electrodes offers advantages far beyond the field of pure electrochemistry. I should like to illustrate this with an example drawn from work in my own laboratory, concerning liposomes. Liposomes are excellent models for biological membranes because they have the same general structure, and can also be prepared in such a way as to incorporate peptides, which are also found in biological membranes. Liposomes interact with mercury electrodes in a very specific and fascinating way. When they encounter a mercury surface, they start to bind, most likely via some lipid molecules that have turned around due to thermally activated "flip-flop" kinetics. Pores are then formed in the liposomes which trigger the release of their inner solutions; and an adhesion-spreading process is initiated that causes the lipids to spread out into islands of adsorbed molecules. The entire process can easily be detected and analysed by recording

University of Greifswald, Institute of Biochemistry, Chair of Analytical and Environmental Chemistry, Editor-in-Chief Journal of Solid State Electrochemistry, Felix-Hausdorff-Straße 4, 17487 Greifswald, Germany,fscholz@uni-greifswald.de 
current-time transients at constant electrode potential [1-9]. Each individual event generates a sharp current peak within a few milliseconds. These can be counted to reveal the stochastic "macrokinetics", i.e., the number of events per unit time. Furthermore, the integration of the current-time transients reveals the "microkinetics", i.e., the rates of the adhesion-spreading processes. Analysis of these data, combined with standard kinetic techniques (Arrhenius plots, etc.), then allows the activation parameters of individual steps to be deteremined and allows the observed membrane properties to be correlated with the membrane composition. Such studies are exclusively possible with mercury electrodes because (i) only a mercury surface allows adsorption of lipid molecules to be performed in a highly reproducible way, (ii) only the mercury electrode surface can be renewed quickly in such way that an extended data set can be recorded reproducibly, (iii) only for mercury can one determine the charge densities of the electrode|solution and the electrode|lipid interfaces with high accuracy. Indeed, the extent and progress of research in the area of liposome-electrode interactions would never have been possible with solid electrodes, and I am convinced that mercurybased techniques will provide invaluable insights into the study of vesicle fusion, and ultimately into the study of cell organelles.

The attempted banning of mercury from research laboratories is well-intentioned, but foolish. When reading the "KEMI Report by the Swedish Chemicals Inspectorate in response to a commission from the Swedish Government" [10], one is tempted to ask what the qualifications of the authors actually were. Concerning the use of mercury in $R \& D$ laboratories the report contains the following paragraph: "Research in the academic world and as part of commercial R\&D efforts often leads to the development of new products. KemI considers that it is important that new applications of mercury and mercury compounds should not come into use and that new products containing mercury should not be put on the market. A general ban on the handling of mercury would counter such a new supply of mercury to society." The authors of the report were obviously unaware of the fact that many mercury electrodes are used in critical applications and are functionally irreplaceable. Of course, replacement is possible in certain instances, and I would be the first to welcome that. But a complete ban is the most primitive method of fighting environmental pollution. Such a policy has the charm of promising $100 \%$ success; however, a childish logic lies behind it. In the $21^{\text {st }}$ century a more intelligent handling of toxic substances is possible for the benefit of all mankind. The case of overzealous mercury legislation reveals the depth of misundertsanding between scientists and politicians, and we scientists must blame ourselves for not having raised our voices early enough! 


\section{References}

[1] D. Hellberg, F. Scholz, F. Schauer, W. Weitschies: Electrochem. Commun. 4 (2002) 305-309.

[2] D. Hellberg, F. Scholz, F. Schubert, M.

Lovrić, D. Omanović, V. Agmo

Hernández, R. Thede: J. Phys. Chem. B 109 (2005) 14715-14726 .

[6] V. Agmo Hernández' F. Scholz:

Bioelectrochem. 74 (2008) 149-156.

[7] V. Agmo Hernández' F. Scholz: Israel J. Chem. 48 (2008) 169-184.

[8] V. Agmo Hernández, M. Hermes, A. Milchev, F. Scholz: J. Solid State Electrochem. 13 (2009) 639-649.

[3] V. Agmo Hernández, F. Scholz: Langmuir 22 (2006) 10723-10731.

[9] V. Agmo Hernández, A. Milchev, F. Scholz: J. Solid State Electrochem. 13

[4] V. Agmo Hernández' F. Scholz: Bioelectrochem. 74 (2008) 149-156.

[5] V. Agmo Hernández, J. Niessen, F. (2009) 1111-1114.

[10] KEMI Report by the Swedish Chemicals Inspectorate in response to a commission Harnisch, S.Block, A. Greinacher, H. K. Kroemer, C. A. Helm, F. Scholz: Bioelectrochem. 74 (2008) 210-216. from the Swedish Government. Stockholm, October 2004. Publisher: Swedish National Chemicals Inspectorate ${ }^{(}$.

$$
\text { (ふりっつ・しょるつ、グライフスヴァルト大、ドイツ) }
$$
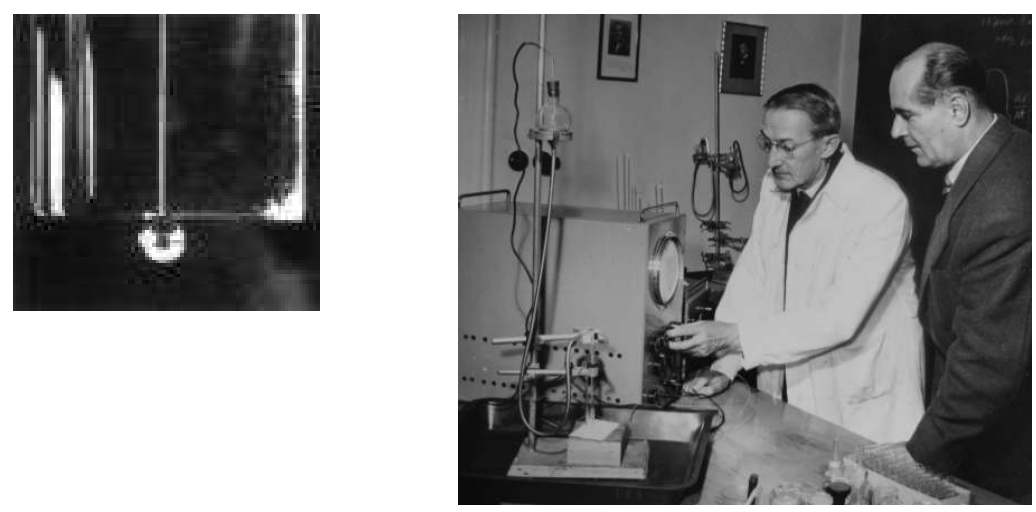

Photos from Dr. Samec to the editor, originally by courtesy of Dr. M. Heyrovský. 